\title{
Development and Outcomes from a Translational Science Curriculum for Pre-Collegiate Students
}

\author{
Andrea S. Lin ${ }^{1 *}$, Julie K. Bray ${ }^{1 *}$, Margaret M. Fettis ${ }^{2}$, Gabriel A. Fernandez Bueno ${ }^{1}$, Julie Bokor ${ }^{3}$, and Mary Jo Koroly ${ }^{3}$ \\ "Authors Lin and Bray contributed equally to this manuscript.
}

${ }^{1}$ Department of Pathology, College of Medicine, University of Florida, Gainesville, FL; ${ }^{2} \mathrm{~J}$. Crayton Pruitt Family Department of Biomedical Engineering, University of Florida, Gainesville, FL; ${ }^{3}$ Center for Pre-Collegiate Education and Training, University of Florida, Gainesville, FL.

Keywords: teaching and curriculum development, clinical and translational science, STEM education

Publication Date: January 24, 2019

DOI: https://doi.org/10.15695/jstem/v2i1.03

\begin{abstract}
Translational science is the cornerstone of biomedicine that transfers laboratory and clinical research to the hospital bedside in various forms of therapeutic interventions. This scientific branch influences public health decisions, the economy, and ongoing research endeavors. The purpose of this study was to develop a youth-friendly Translational Science course that introduced students to translational science concepts, then examine course outcomes and effects on career choices. The seminar course involved 18-contact hours with 20 high-school juniors ( $n=10$ / Summer 2016 \& Summer 2017). The curriculum encompassed the fundamentals of the five translational science phases as well as how to understand scientific readings and conduct efficient research database searches. A concluding student-presentation on a topic of the student's choosing ensured each student had a sufficient understanding of translational science, use of PubMed for original research articles, and demonstrated the student's ability to apply the concepts individually. Analysis of end-of-course and follow-up surveys showed that the majority of students understood the material, felt the course met their expectations and influenced long-term professional goals. These data suggest that exposing students earlier in their career (pre-collegiate) to the importance and structure of translational science could have long-term benefits towards influencing career choices in STEM.
\end{abstract}

\section{INTRODUCTION}

Engaging students in science, technology, engineering, and mathematics (STEM) learning experiences is increasingly important for student success at all levels of education. Early exposure to STEM challenges students and creates positive impacts that influence the entire spectrum of learning (Secretary, 2016). Thus, an understanding of how STEM topics move from the lab setting to consumers could benefit young scientists interested in pursuing a STEM career. This process is termed translational science, and this paper describes the development and outcomes from a course tailored to teach high school students about each of the translational science phases, while concurrently exposing students to the necessary tools and essential scientific concepts needed to understand this subject.

Translational Science Description. Translational science, colloquially known as bench-to-bedside, is the stepwise process of applying foundational research discoveries to benefit the clinical setting and positively impact the general population. The initial feed into this process begins with observing a clinical problem, proposing a research-based question to explore the problem, and offering a potential, effective solution in the real-world setting. Following the observation of a clinical problem, translational science is separated into five sequential, distinct translational-science phases (T-phases) termed T0, T1, T2, T3, T4 (Gannon, 2014). Briefly, T0 refers to the basic biomedical research phase, $\mathrm{T} 1$ involves phase I clinical trials of human subjects, T2 is translation into patients through phase II and III clinical trials, T3 applies the therapeutic modality into practice, and finally T4 aims to apply the work to communities and includes analysis of longterm effects (Blumberg et al., 2012; Fort et al., 2017) (Fig. 1).

For the past two decades, research studies have transformed from separate, individualized efforts into cross-disciplinary approaches with collaborations occurring across departments, universities, states, and countries (Luke et al., 2015). Formation of these science teams to move lab research into the clinic have become increasingly more important across all STEM fields. Thus, understanding the pro- 


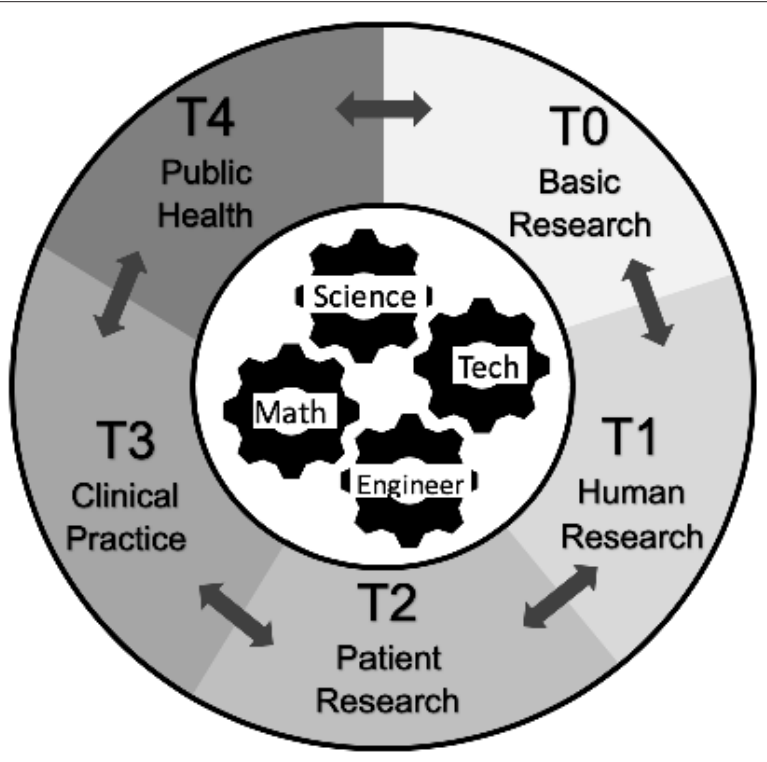

Figure 1. The Translational Science Wheel. Translational Science is a sequential and bi-directional process of bringing basic research to patient populations. This process has been broken down into five distinct phases (T0, T1, T2, T3, T4) and requires a multi-disciplinary approach encompassing numerous fields, especially science, technology, engineering, and math.

cess of translational science could bolster communications across these borders for educational and professional benefit. Effective learning of translational science skills requires knowledge of each distinct T-phase, familiarity with search platforms, and an understanding of how to bring multidisciplinary teams together to tackle a research problem (Rubio et al., 2010). These skills take years to develop, thus necessitating early exposure to the topic and its associated technologies.

Currently, development of coursework on the subject of translational science is limited and challenging, often requiring design of an individualized curriculum for trainees based on the individual's background (Rubio et al., 2010). To initiate a movement to address this deficit, the National Institutes of Health developed the Clinical and Translational Science Award to promote education and training of multi-and inter-disciplinary investigators and research teams at medical research institutions (NCATS, 2018). However, there are few publications on PubMed or Google Scholar about formal or informal training on the topic of translational science for high school students who have a STEM interest. Examination of course catalogs from the top ten STEM U.S. public high schools also indicate a lack of access to translational science coursework. Thus, delineating a curriculum tailored for a secondary education setting is critical for these students. Knowledge on this topic would supplement the core skills necessary for young scientists to solve difficult problems, evaluate data, and make sense of information received from the classroom and media. Translational science further prepares students for a workforce that relies on application of learned knowledge in STEM to develop realistic, attainable solutions (Manson et al., 2015).

Course Development and Outcomes. In this study, we outlined a curriculum developed specifically for pre-collegiate students interested in STEM and examined how the design and implementation of a proposed translational project enhanced their retention of the course materials. Students who participated in this translational science seminar were exposed to a diversity of STEM-related career paths and technological aides necessary for success in the sciences. This seminar was conducted concurrently with their apprenticeship in a research lab. The bulk of course materials were presented through oral transmission of prepared PowerPoint slides in a lecture setting. However, all course materials were supplemented with a discussion and interactive module activities that individually facilitated the students' comprehension of the scientific concepts. We asked the following research questions: (1) Was the course material designed and presented in a way that was amenable to all learning styles and lead to course satisfaction? (2) Did the course positively influence STEM career choices?

Our analyses indicated that the course material positively influenced the youngsters' perspectives on STEM career opportunities. Introducing young students to the concepts and applications of translational science through real-world research problems broadened their understanding of the current challenges in medicine. Descriptions of lecture topics, objectives, and the interactive activities are included in this paper. Our findings from short-term $(<24$ hours post-course completion) and long-term ( $>6$ months post-course completion) surveys confirmed that nearly all students benefited from this early exposure to translational science coursework.

\section{METHODS}

Program Structure. The Student Science Training Program (SSTP) within the Center of Precollegiate Education and Training (CPET) at the University of Florida (UF) is a seven-week residential summer program on the Gainesville, FL campus. The program is geared to expose academically talented pre-collegiate students to research in a STEM-related field through three academic components: hands-on laboratory research, a science lecture series, and a UF Interdisciplinary Honors Seminar Course. This study focused on the development and evaluation of an honors seminar course about translational science that was offered during the SSTP in Summers 2016 and 2017.

UF Interdisciplinary Honors Seminar Course. The purpose of the honors seminar courses within the SSTP is to introduce and enrich students' knowledge of research methods, techniques, and findings on a specific topic of their choosing. 
During Summers 2016 and 2017, the Translation Science course was one of nine seminar options offered to the SSTP students. The course was wholly designed and taught by graduate student volunteers. At the beginning of the SSTP in 2016 and 2017, students self-selected their top three seminar preferences. The CPET-SSTP staff then placed students in a seminar based on preference and availability. Class meetings were held on bi-weekly evenings for one and a half hour sessions for a total of 18 contact hours. The Translational Science honors seminar integrated experiential learning (active listening, note-taking, conducting a mini-project) with

Table 1. Student Demographics. Self-identified student information for participants in the Translational Science Seminar from 2016 and $2017(\mathrm{n}=20)$.

\begin{tabular}{lcc}
\hline Sex & Male & $6 / 20=30 \%$ \\
& Female & $14 / 20=70 \%$ \\
\hline Hometown & Florida & $16 / 20=80 \%$ \\
& Non-Florida (US) & $4 / 20=20 \%$ \\
\hline Ethnicity & Caucasian & $7 / 20=35 \%$ \\
(self-reported) & Asian & $4 / 20=20 \%$ \\
& African American & $1 / 20=5 \%$ \\
\hline Academic Year & Hispanic & $1 / 20=5 \%$ \\
\hline
\end{tabular}

round-table discussions and hands-on group activities. The course culminated in formal presentations describing how the application of translational science (T0-T4) could solve a clinical problem of each student's choosing.

Participants. The 20 total participants of the SSTP Translational Science seminar had successfully completed their junior year of high school and were poised to begin their senior year in the fall. Males represented roughly a third of the students (30\%) and females represented about two-thirds of students $(70 \%)$ (Table 1$)$. The majority of the students were from Florida (80\%), but there were four students $(20 \%)$ from other US states. Ethnicities were self-reported; $35 \%$ of the students identified as Caucasian, 20\% were Asian, 5\% were African American, 5\% were Hispanic, and 35\% were un-reported. The class of 2016 enrolled 10 students with 10/10 successfully completing the seminar course. The class of 2017 also enrolled 10 students with a 100\% completion rate.

Survey Development. Two separate surveys were administered for evaluating course effectiveness and student learning.

Survey 1: End-of-Course Evaluation (SSTP Program Evaluation). The first optional survey distributed to the students was the formal SSTP program evaluation (Table 2). This anonymous form was administered to students within 24-hours of completing the seven-week seminar without the course instructors present to encourage surveyor honesty. In

Table 2. End-of-Course Evaluation (SSTP Program Evaluation). This thirteen-question survey was created by the CPET for the SSTP staff to assess overall course satisfaction. Survey questions and response options allowed students to give direct feedback on specific course components.

\section{Question on Course Satisfaction (Response Options: Very Satisfied/Satisfied, Neutral, Dissatisfied/Very Dissatisfied)}

How satisfied overall were you with this course?

\section{Likert Scale Questions (Response Options: Strongly Agree/Agree, Neutral, Disagree/Strongly Disagree)}

This course met or exceeded my expectations.

Enough background information was presented to understand the topic(s) discussed in class.

The articles, lectures, and information presented were challenging, but I was able to understand each.

Topics were interesting and held my attention throughout the seminar.

Everyone had an opportunity to participate in discussions. The instructors created an environment where different ideas were welcomed.

\section{Likert Scale Questions (Response Options: Strongly Agree/Agree, Neutral, Disagree/Strongly Disagree)}

The instructor was knowledgeable on the topic(s) discussed in class.*

The instructor was prepared and able to communicate clearly and effectively.*

The instructor was approachable, willing to answer question, and provide additional help as needed.*

\section{Open-Ended Questions}

Please list some examples of the instructor's strengths as a teacher as well as what he/she did that was helpful to your success.*

Please give any feedback for improvement and/or comment on any teaching weaknesses of the instructor below (especially if you indicated disagree or strongly disagree for any of the above statements).*

What were your intentions and/or expectations when you selected this course as one of your top choices?

Please provide additional feedback about the course and comment on any overall strengths and weaknesses.

* the following survey questions were not analyzed as part of this manuscript, but were part of the formal survey and are therefore included 
this 13-question survey, students were asked to assess the course content and instructor quality on a Likert scale. The open-answer questions allowed students to comment on course strengths, weaknesses, instructor quality, and leave suggestions for improvement. All twenty students enrolled in the course opted to complete the survey. This study was approved by the University of Florida Institutional Review Board (IRB201702798).

Survey 2: Program Outcomes Evaluation. The second optional survey evaluated course learning outcomes and influences on future career paths (Table 3). This survey was based on the Social Cognitive Career Theory (SCCT) (Lent, 2004; Lent et al., 1994). The SCCT is an established survey model used as a framework for studying interactive learning experiences that influence career development and academ- ics in both high school and college (Flores, 2006; Kier et al., 2014). The SCCT evaluates six key variables that are associated with career development: (1) interest (2) expectations (3) support (4) goal (5) efficacy (6) disposition, defined as the tendency to experience a positive or negative effect (Lent and Steven, 2000). The basis of this model's output is personal inputs; therefore, it can be applied to any age group and focuses on an individual's influences.

In our study, the survey questions were written by the course instructors to apply these six validated, fundamental properties to holistically determine the personal impact of the Translational Science course on the high school students. Each of the six categories were equally represented by three questions to gauge student response consistency (Table 3) for a total of eighteen questions. Students were blinded to the SCCT category of each question. The five-point Likert-

Table 3. Program Outcomes Evaluation and SCCT categories. The Program Outcomes Evaluation was created by the course instructors and included three questions for each of the six validated, fundamental properties. The eighteen Likert scale questions gauged the professional and personal impacts of the Translational Science course on the students.

\section{LIKERT SCALE QUESTIONS (STRONGLY AGREE/AGREE, NEUTRAL, DISAGREE/STRONGLY DISAGREE)}

The Translational Science course increased my interest in the Translational Science field.

I am interested in taking more Translational Science coursework in college if additional classes are offered.

I am interested in pursuing a career that has a Translational Science component.

The content of the Translational Science course gave me an understanding of how research discoveries are applied in the clinic to improve population health.

Professions in the Translational Science field offer a stable career path.

Translational Science improves clinical medicine.

The final presentation allowed me to apply the material discussed in lectures.

Having face-to-face discussions with the Translational Science faculty panel was beneficial toward developing my professional goals.

The Question-and-Answer Session with Professional Students (MD, DMD, PA, or PhD) was beneficial for post-high school planning.

At the conclusion of the Translational Science course, I was able to independently develop a (hypothetical) project and carry it through all the phases of Translational Science.

The information discussed in the Translational Science course influenced my selection of a potential/current undergraduate major.

The Translational Science course influenced my long-term professional goals.

I would feel comfortable discussing the 5 phases of Translational Science (T0 - T4) to a peer.

I am confident in my ability to contribute to the Translational Science field in my future career.

I would do well in a collaborative environment like the Translational Science field.

I would recommend the Translational Science Course to other high school students interested in a STEM field.

The course content provided career exploration in the STEM fields with relation to Translational Science.

Translational Science is a valuable scientific field.

\section{SHORT-ANSWER QUESTIONS}

Please provide comments on how the Translational Science course improved your understanding of how therapeutic modalities are discovered, developed, and implemented into the clinical setting.

Please provide comments on how the final project helped you apply what you learned in the Translational Science course.

Please provide comments of how the Translational Science course influenced your short-term and long-term professional goals.

Please provide any additional positive or negative feedback.

\section{SCCT CATEGORY} ASSESSED

Interest

Interest

Interest

Expectations

Expectations

Expectations

Support

Support

Support

Goal

Goal

Goal

Efficacy

Efficacy

Efficacy

Disposition

Disposition

Disposition

TYPE OF QUESTION

Open-Ended

Open-Ended

Open-Ended

Open-Ended 
scale was used for responses to allow non-biased quantification (Likert, 1932; Vagias, 2006). The survey also included four short-answer questions to allow open feedback (Table $3)$.

The Program Outcomes Evaluation was administered via e-mails containing individualized links through the online Qualtrics system. For students under the age of 18-years, parent and/or guardian approval was received via e-mail exchanges or phone conversations. Students enrolled in SSTP during Summer 2016 received the survey approximately 18 months after course completion; students who took the seminar in Summer 2017 received the survey about six months following course completion. Nineteen students opted to complete the survey and fourteen of the nineteen students completed the open-ended responses. This study was approved by the University of Florida Institutional Review Board (IRB201702798).

Quantification of Survey Results. For both surveys, on questions that utilized the five-point Likert scale, both the "strongly agree", "agree" categories and the "strongly disagree", "disagree" categories were compounded. Response frequencies and percentages were determined for each question, and analysis was blinded. Prism software was used for quantification and graphing of the results (GraphPad Prism, La Jolla, CA). Due to limited sample size, statistical analysis was not performed on the quantitative data.

Thematic Analysis Method for Open-Ended Questions. The short-answer questions provided students an opportunity to elaborate on thoughts and topics that were not covered in the surveys. Students discussed thoughts on the course and commented on specific course components, such as the final project. The open-ended question that probed about short-term and long-term professional goals did not define a timeline but was open to interpretation by each individual student.

The aim of the open-answer analyses was to decode the pooled responses and find common themes derived from the participants' language about course outcomes and expectations. The co-instructors collaboratively reviewed the open-ended answers and compared responses from 2016 to 2017, categorized the responses based on recurrent words, and reached a consensus about text interpretation and its significance.

During analysis of the open-ended responses, words used, context, specificity of responses, and recording patterns were considered. Saturation, which was determined by the redundancy of data and respondent validation of categories, occurred due to question constraints in the first and second surveys. The semantic themes identified were unique from questions asked and were commonly occurring vocabulary or descriptions. These open coded responses that captured interesting information were tied back to course content (Glaser, 1965).

\section{RESULTS}

Part 1: Course Development. Course Curriculum, Lecture Materials. The course learning objectives were focused on the five phases of translational science: T0, T1, T2, T3, and T4. Each lecture was structured so that one of these five phases was featured as the main topic, with supporting materials to supplement the lesson. Scientific terms necessary for understanding of the translational phase were introduced in the background of the lecture, and relevant examples of biomedical or engineering discoveries were included. Each student's interest in specific STEM fields and his/her corresponding career goals were gauged during the first class. These interests were integrated into the lecture materials and used as examples, when relevant, to favor student engagement in the course.

The main lecture topics and corresponding learning objectives are outlined (Table 4). The course included five interactive activities (Table 5) that promoted discussion and engaged the students in hands-on learning. For the final presentation, students identified a clinical need and developed a hypothetical therapeutic modality to address that need. Students were required to apply the lecture material to discuss how his/her modality would move through the T0-T4 phases of Translational Science during the 8-minute oral and PowerPoint presentation (Table 6). Students were asked to pick the topic of his/her final presentation and were mentored directly by one of the instructors throughout the duration of the course.

Career Panels. To expose students to the career possibilities in Translational Science and provide perspective on required education and training, two separate Question \& Answer (Q\&A) sessions were hosted during the last two class sessions. The professional student Q\&A session had a panel of 3-4 graduate students from a variety of STEM-related fields (medical school, dental school, physician assistant school, nursing school, biomedical engineering graduate program, biomedical sciences graduate program). The professional occupation Q\&A session involved faculty members or industry professionals that were in different T0-T4 fields who were working on unique research questions in the respective T-phase. The panel was diverse with representation of each T-phase so students could question professionals on the real-world applications of each phase. Professional student and faculty panel participants were carefully selected to match the career goals of the students.

Graduate Student Development. The course had a positive impact on the four graduate student instructors. This course provided an avenue for the instructors to prepare for possible academic faculty positions. Instructors worked col- 
Table 4. Curriculum outline. Each lecture topic in the Translational Science course and corresponding learning objectives summarize the content covered in the PowerPoint lectures.

\begin{tabular}{ll}
\hline Lecture Topic & \multicolumn{1}{c}{ Learning Objectives } \\
\hline & What is Clinical and Translational Science (CTS)? \\
Intro to Clinical \& Translational Science & Overview of the 5 stages of CTS (Big Picture) \\
& CTS as an emerging initiative of the NIH and CTSA
\end{tabular}

What is a therapeutic modality?

T0: Preclinical Research

Types of therapeutic modalities

Major types of research techniques/approaches

The "scientific method" process

What is PubMed? What is Medline?

The Power of PubMed

Know how to perform basic literature searches using PubMed

Apply PubMed to your own current research/learning

What are patents? Why are they important?

Know the different types of patents

Patents and Papers

Scientific publication

Know publication "anatomy"

Process and purpose of peer review

Main purpose of Phase I Clinical Trials

Conducting Phase I Clinical Trials

T1: Clinical Trials, Phase I

What is an Investigational New Drug (IND) application?

What is the Institutional Review Board (IRB)?

What is ClinicalTrials.gov and how can it be used?

Main goals of Phase II vs III Clinical Trials

How Phase II and III Clinical Trials are typically conducted

T2: Clinical Trials, Phase II and Phase III

Categories of clinical trials

Clinical trial design considerations

Examples of Phase II and III Clinical Trials

Types of engineering, focus on biomedical engineering

Translational Engineering

The "engineering method" process

How to become a biomedical engineer

Food and Drug Administration (FDA) device approval

Goals of T3: from guidelines to health practices

Implementation, dissemination, diffusion

Phase IV Clinical Trials

T3: Health Practice, T4: Health Impact

How is T3 is typically conducted

Goals of T4: from practice to health impact

T4 economic assessment, government regulation, and health disparities

Special considerations of T4: size, duration, costs, and target population

laboratively to develop all course content including a syllabus, learning objectives, lecture materials, and interactive activities, and networked with professionals in the translational science field for the panel discussions. Each graduate instructor had a positive experience mentoring high school students and reinforced his or her own understanding of
Translational Science. The students who took the course provided valuable, constructive feedback on the teaching techniques of each graduate student in the End-of-Course Survey, which could be used by the instructors to enhance future teaching experiences.

In return, the graduate student instructors were able to 
Table 5. Description of Interactive Module Activities. Module activities were interspersed throughout the lectures and students either worked individually or in small groups with instructor guidance.

Activity Name

Power of PubMed

Choose Your Own Paper

Design a Paper

Clickin' with ClinicalTrials.gov

Clinical Problem Solving with Engineering

\section{Activity Description}

Students learned how to conduct a search in PubMed and utilized all the databases of PubMed, the primary search engine used by both research scientists and clinicians.

Each student selected a paper related to his or her summer research apprenticeship. Students examined the anatomy of their scientific paper: abstract, introduction, methods, results, conclusion, and discussion. After understanding the basics on a research publication, students identified the varying strengths and weaknesses of their paper.

This interactive exercise prepared students to consider necessary components for paper writing. Information on an authentic research project was detailed in a PowerPoint presentation.

Details provided to students included rationale for the project, background information on the project, current experiments and results from the project. Following the presentation, students were placed into 3 teams and collaboratively drafted a theoretical paper that included an introduction, results, and conclusion/discussion. Students designed a poster in-class to showcase their outlined paper components.

Students learned how to effectively use ClinicalTrials.gov to find a Phase I, II, or III study. Students became familiar with website format, search functions, and briefly analyzed a couple reports emanating from current and archived trials across the 50 states and 204 countries.

Students were given a biomedical problem (blocked artery) and were encouraged to design a device to restore normal arterial flow. Students followed the engineering method and constructed a prototype using low-cost materials. Module funded by NSF DMR 1455201.

Table 6. Translational Science Final Project Rubric. The components outlined in the rubric required students to understand the broad application of their STEM product, while effectively presenting to their high school peers in a manner that would be understandable to a lay-audience. Students were graded on their presentation and on their oral performance.
Grade:
A
B
C (or lower)

Presentation format/or- Presentation of information is in a logiganization: Background cal sequence (relevant background) and \& Timing hold's the audience captive. Presentation is capped at 8 minutes. words. If applicable, used notes only as a reference.

Font Font (titles and text) on all slides is appropriate to be read at a distance

Graphics

All slides present 1 idea and include supporting facts (if needed). Pictures are only included when appropriate and necessary.

\begin{tabular}{c}
\hline Citations \\
\hline Content: Real-World \\
Application \& Sum- \\
mary
\end{tabular}

All slides used MLA format to consistently cite all references

Presentation contains major points covered from lecture and is supported with convincing arguments and data and includes data from an original research article with a summary slide

Material Covered: It was clear the presenter knew the topic T-Phases and Clinical well and included relevant examples for Trial Phases
Font (titles and text) on $80 \%$ of slides is appropriate

All slides present either 1 idea or only have supporting facts (if needed). Pictures included are not always necessary and do not add to enhance the slide.

$80 \%$ of slides used MLA format to consistently cite all references
Presentation of information is either illogical or not interesting to the audience. Background is not sufficient. Presentation exceeded the 8-minute limit or was under-limit

Low voice and proper pronunciation. Notes are relied on heavily.

Presentation information is neither logical nor interesting and is $>10$ minutes or $<5$ minutes.

Mumbling \& incorrect pronunciation. Read straight from notes.

Font (titles and text) on most slides is not appropriate

Slides present more than 1 idea without supporting facts (if needed). No pictures included at all.

$<50 \%$ of slides used MLA format to consistently cite all references

Presentation contains major points covered from lecture and is partially supported with convincing arguments and data with a summary slide

Presentation did not cover lecture material and is not supported with adequate data or a summary slide

The presenter understood the topic relatively well and included examples for $80 \%$ of the T-phases and distinguished between Phase I-III clinical trials with minor difficulty. Majority of questions from the audience $(80 \%)$ are answered

clearly \& completely
The presenter had a vague understanding of the topic with no distinction between Phase I-III Clinical trials. Few questions from the audience $(20 \%)$ are answered
All questions from the audience $(100 \%)$ are answered clearly \& completely 
offer relatable, unique support to high school students that would not be as readily available from faculty instructors. These support systems included current insights into choosing a college or post-high school path, deciding a major, and academic admissions applications. This seminar placed an emphasis on the application of STEM through translational science and provided a small-group learning environment for both instructors and students to enhance higher-order thinking.

Part 2: Course Outcomes. A total of 20 students enrolled in the "Translational Science" Seminar during the two summer sessions from 2016-2017. All 20 students completed the course, compiled a final project, and received a final grade. The response rates for the end-of-course evaluation were $20 / 20(100 \%)$. For the online follow-up questionnaire, 19/20 students $(95 \%)$ completed the survey.

End-of-Course Evaluation of the Translational Science Course. The students' interest in the course was evident by the majority $(72 \%)$ indicating that the course met or exceeded their expectations, while $22 \%$ of students reported neutral about the course (Fig. 2a). The background material was sufficient for understanding the information presented $(100 \%$ strongly agree/agree), and the bulk of information was presented in a way that was challenging but understandable (89\% strongly agree/agree) (Fig. 2b-c). Students continued to stay attentive throughout the duration of the course because they found topics interesting (Fig. 2d), which was evident to the instructors during daily observations and reflected in the survey with a $72 \%$ strongly agree/agree response. Overall, the course welcomed different ideas during discussions, and $94 \%$ of students were extremely or moderately satisfied with the course (Fig. 2e-f). These positive impacts indicated that the course was successful in teaching the T0$\mathrm{T} 4$ phases of translational science with relevant examples in the lecture material or through PowerPoint slides that garnered student interest. The translational science course met students' expectations through lecture materials, interactive activities, and the two career panels.

Final Project Assessment. The final project had defined learning objectives assessed by a rubric provided to students at the start of the course (Table 6). Each student's final product was evaluated using five distinct categories. These categories were relevant to the learning objectives, so students could apply the course material to a topic of interest to them. Most students (85\%) demonstrated an understanding of the T0-T4 phases but had more difficulty in comprehending how those were different from the Phase I-III Clinical Trials (70\%) (Fig. 3a-b). All students adequately prepared and understood the background of their project $(100 \%)$ but did not always tie in the relevance to a real-world application or provide a summary that concisely described the project holistically (75\%) (Fig. 3c-e). The majority of the student-se- lected STEM-topics were in science and engineering, with one technology-related project, and no representation of math (Fig. 3f).

Grading Categories and Grade Distributions. For the overall seminar grade, there were three separate components consisting of Participation, Homework Assignments, and the Final Presentation with sub-categories (Table 7). The final average for the course in both 2016 and 2017 was an "A". Only three students total were assigned a "B" as the final grade. The grade distribution from each category is delineated in Table 7. These grades show that students completed assignments on time, met requirements, and were successful in presenting their final project.

Program Outcome Evaluation of the Translational Science Course. Students that completed the course in 2016 were administered the survey approximately 18 months following course completion, at which time they had successfully graduated from high school. From this student cohort, the strongest responses were in course expectations, disposition, and support; in all three categories $89.0 \%$ of students strongly agreed/agreed that the course positively influenced these factors, and there were no students that disagreed/ strongly disagreed (Fig. 4a). To a slightly lesser extent, $78.0 \%, 63.0 \%, 63.0 \%$, of students strongly agreed/ agreed that the course improved their efficacy, goals, and interest in translational science, respectively. For these groups, less than $10.0 \%$ of students strongly disagreed/disagreed that Translational Science would impact overall efficacy, goals and interest (Fig. 4a).

Students that completed the course in 2017 received the survey 6 months following course completion had decreased satisfaction in course expectations (80.0\%), disposition (80.0\%), and support (73.3\%) compared to the 2016 cohort. This trend continued in efficacy, interest, and goals where respectively $63.3 \%, 60.0 \%$, and $60.0 \%$ of students strongly agreed/agreed, and $23.0 \%, 37.0 \%$, and $27.0 \%$ of students were neutral regarding course impacts in these categories (Fig. 4b). Overall, the students were enthusiastic about the material covered in the translational science course with positive responses in each of the six social cognitive career categories (Fig. 4c).

Open-Ended Student Feedback. The open-ended questions from the Program Outcomes Evaluation probed students' thoughts on translational science process (Question 1, $14 / 19$ responses, 5/19 no response), the application of course content (Question 2, 13/19 responses, 6/19 no response), and impacts on career goals (Question 3, 13/19 responses, 6/19 no response). Table $8 \mathrm{a}$ includes student answers to each of the questions, which indicated positive course outcomes.

Within each individual short-answer question, there were consistent patterns and themes identified. For the first short-answer question, students indicated that the course introduced them to the translational science process as a sub- 

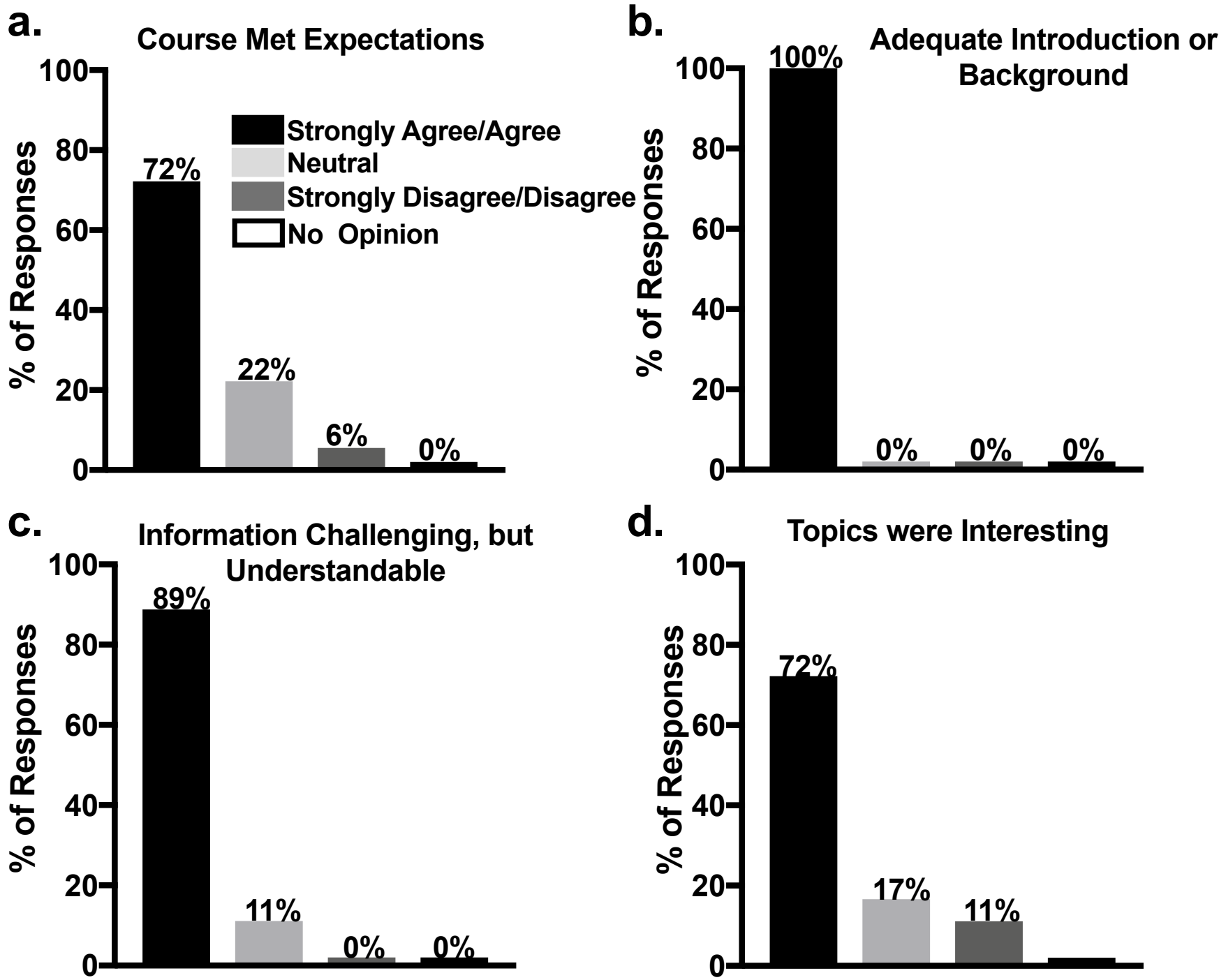

d.

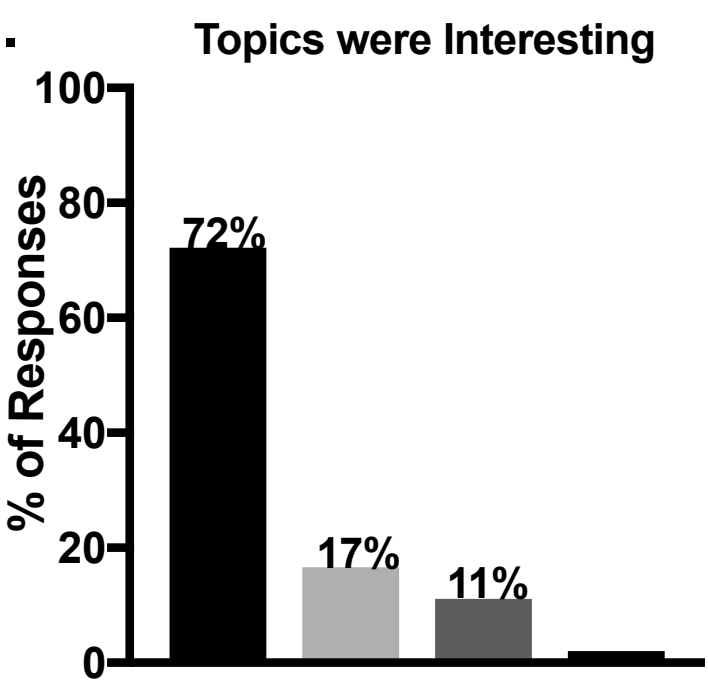

e. Different Ideas Were Welcomed

f. Overall Course Satisfaction
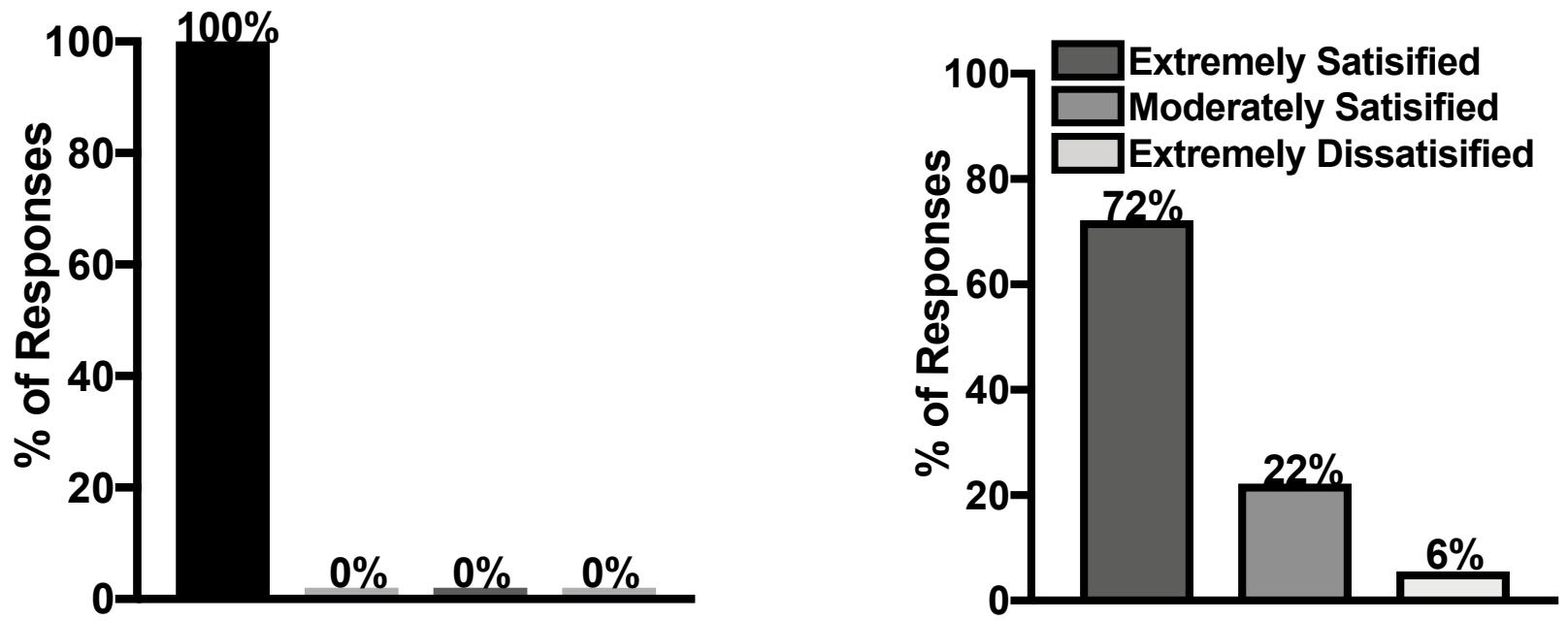

Figure 2. End of Course Evaluation Results. Student survey responses immediately following completion of Translational Science Course according to a five-point scale $(n=20)$. The questions in this survey were (a) this course met or exceeded expectations; (b) enough background information was presented to understand the topics discussed; (c) the articles, lectures, and information presented were challenging, but I was able to understand the material; (d) topics were interesting and held my attention throughout the seminar; (e) everyone had an opportunity to participate in discussions; the instructors created an environment that welcomed many ideas and (f) overall satisfaction with the course. 
a.

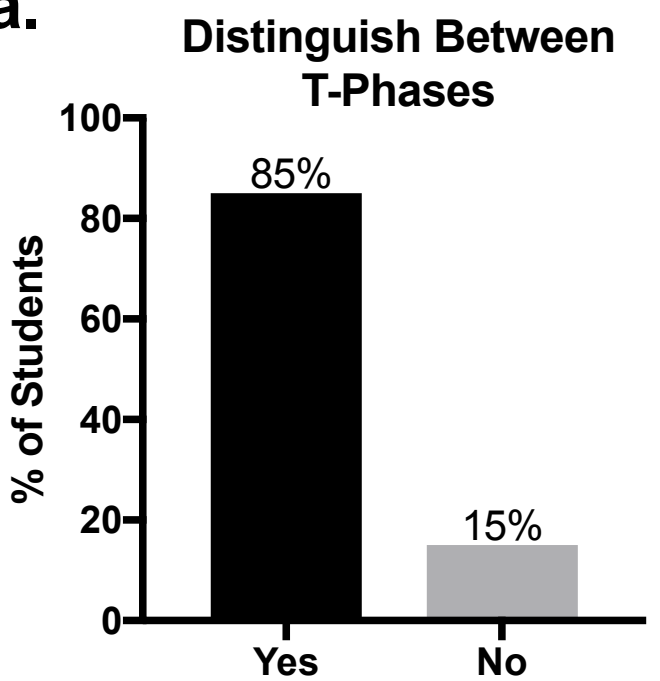

C. Background Information
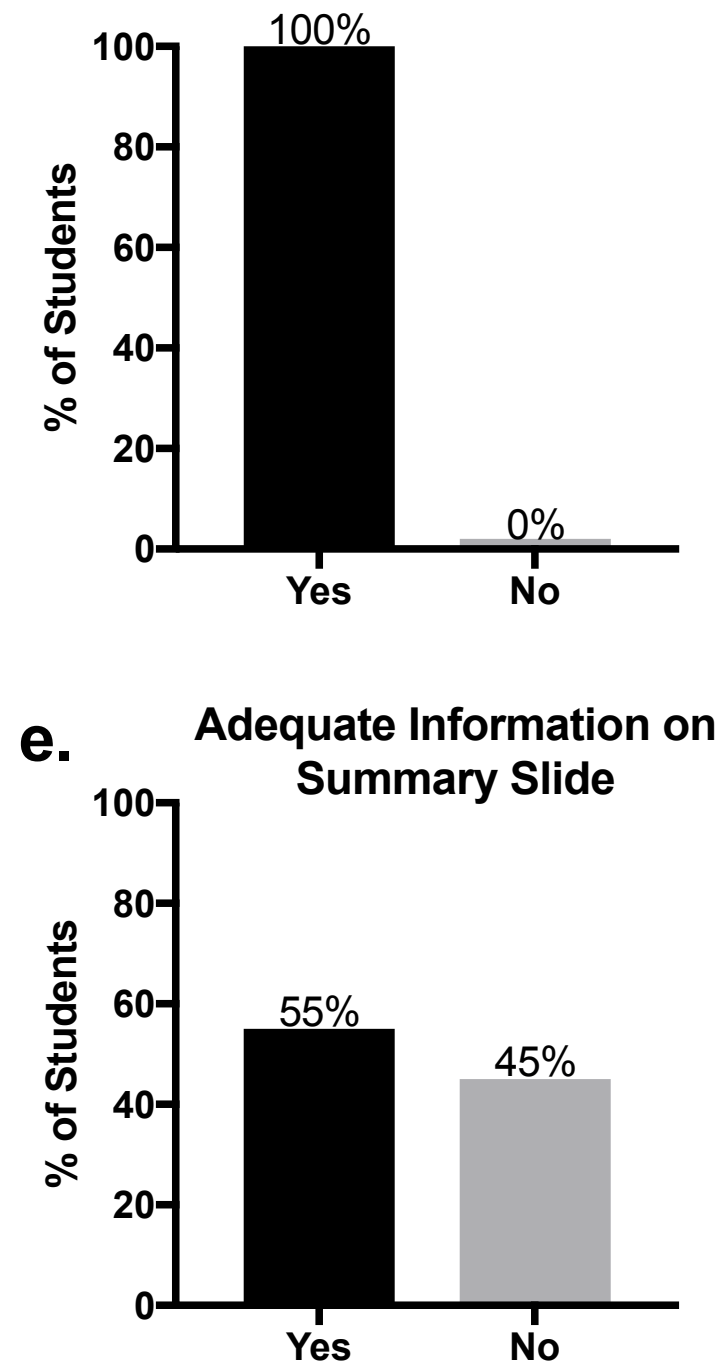
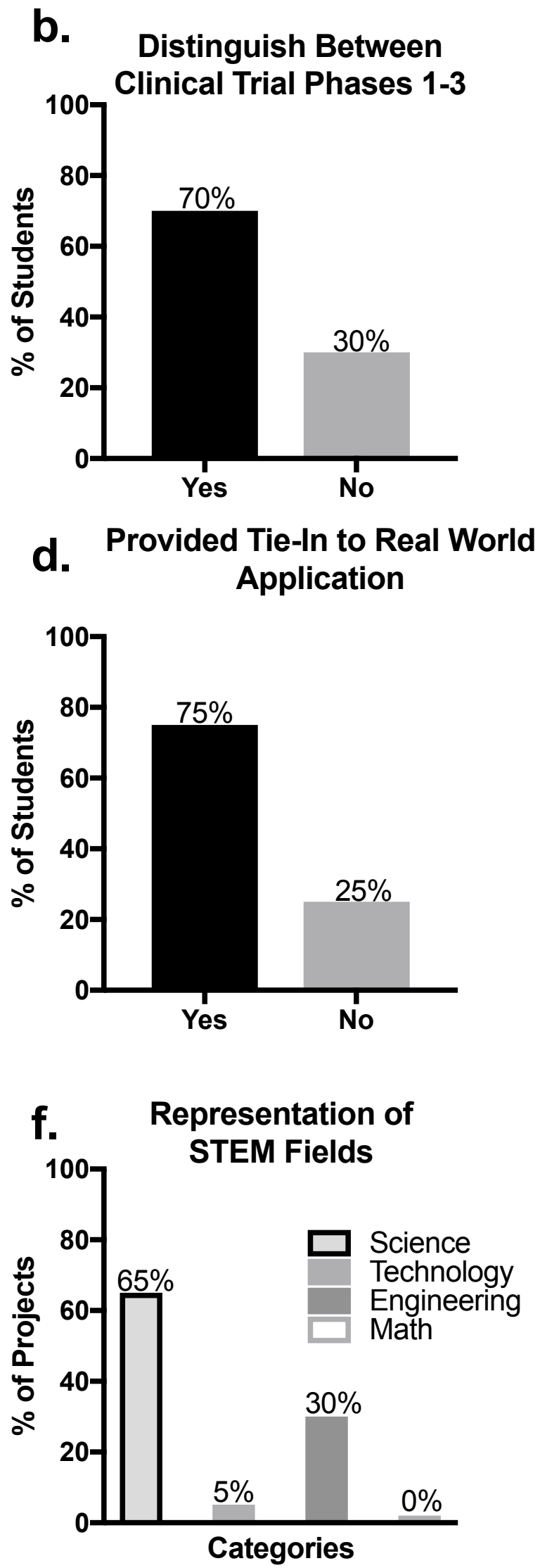

Figure 3. Final Project Assessment. Student final project outcomes are reflective of effective learning ( $\mathrm{n}=20)$. Grading of the final project was categorized into 5 subsets including ability to distinguish between (a) T-phases and (b) clinical trial phases, (c) providing adequate background information, (d) specifying an application to the real-world setting, and (e) including a summary slide at the conclusion of the presentation. 
Table 7. Grade Distributions. Grading categories were separated into participation (40\%), homework assignments (20\%), and the final presentation (40\%). Each student's grade distribution per category was calculated as a percentage of total for a final course grade.

\begin{tabular}{lcc}
\hline Category & \% of total grade & \multicolumn{1}{c}{ Grade distribution among students (n=20) } \\
\hline & & A \\
\hline Participation & $\mathbf{4 0}$ & $90 \%$ \\
\hline Discussions, Clickin' with Clinical Trials, Power of PubMed & 15 & $10 \%$ \\
Design a Paper & 10 & $100 \%$ \\
Clinical Problem Solving with Engineering & 10 & \\
Q\&A Career Panels Preparation & 5 & $0 \%$ \\
\hline Homework Assignments & $\mathbf{2 0}$ & \\
\hline Choose Your Own Paper (PubMed Activity) & 10 & $70 \%$ \\
Article Reading & 10 & $30 \%$ \\
\hline Final Presentation & $\mathbf{4 0}$ & \\
\hline Weekly Progress Assessment & 10 & \\
PowerPoint Quality & 15 & 15 \\
Oral Presentation & & \\
\hline
\end{tabular}

ject matter, which was more complex than they had previously assumed. Two sample student responses to illustrate the internal theme are, "It helped further explain how a drug starts from bench-side to bedside. Helped me understand the different phases of translational science and what happens in each phase. Also, helped me understand the new factors that are added to determine the efficacy of a new treatment." and "The course placed the difficulty of transferring research and ideas into the actual therapies we see in real life into context. The process is so much longer and more expensive than I ever imagined."

The second short-answer asked students about the effects of the final project. An internal theme from the students' responses was that the project gave them a real-life perspective on a translational science problem. A student response that demonstrated this theme stated, "The final project helped me apply what I learned in the Translational Science course to the research that I was conducting at the USDA. While at UF, I did research about small hive beetles and their effect on honeybee species. From the knowledge that I gained from this course, I was able to put together a presentation that reflected what I learned in Translational Science. I thought that this project cemented the knowledge gained throughout this course and I would heavily recommend that the final project continue to be a crucial part of this course."

Finally, in the third question, six of the thirteen responses mentioned the words 'long-term goal' or alluded to the course affecting their goals post-college. Four responses directly stated that the course affected their research goals or future career plans but did not specify what those plans entailed.

In addition to identification of internal themes, transcript analysis of the open-ended questions in the Program Outcomes Evaluation were pooled and then coded for frequency as outlined in the methods section. Three themes that frequently emerged from the answers were "learning", "influence", and "understanding." A subset of student answers is outlined in Table $8 \mathrm{~b}$. Fifteen students commented on how much they learned in the course. Six student comments mentioned the influence of the course or alluded to how the course influenced their understanding on translational science topics. Nine student comments indicated increased understanding of course material or course application.

Eight students had goals that matched up with components of the translational science wheel. Specifically, these students' comments indicated an interest in pursuing a research career that is directly translatable to the clinic such as helping to conduct clinical trials or working with products that are in development. While students did not mention moving between the phases of translational science, there was interest in applied research and even one student mentioned working in science policy.

\section{DISCUSSION}

Translational science is an emerging field to bridge the gap between scientific research, clinical practice, and public health. The fast rate of advancing STEM innovations and increased need for STEM workers necessitates training in translational science (Noonan, 2017). Proper retention and recruitment for academic and career development in Translational Science requires pipeline programs as early as middle and high school students (Nearing et al., 2015). Currently, high school curriculums and activities have fundamental 
a.

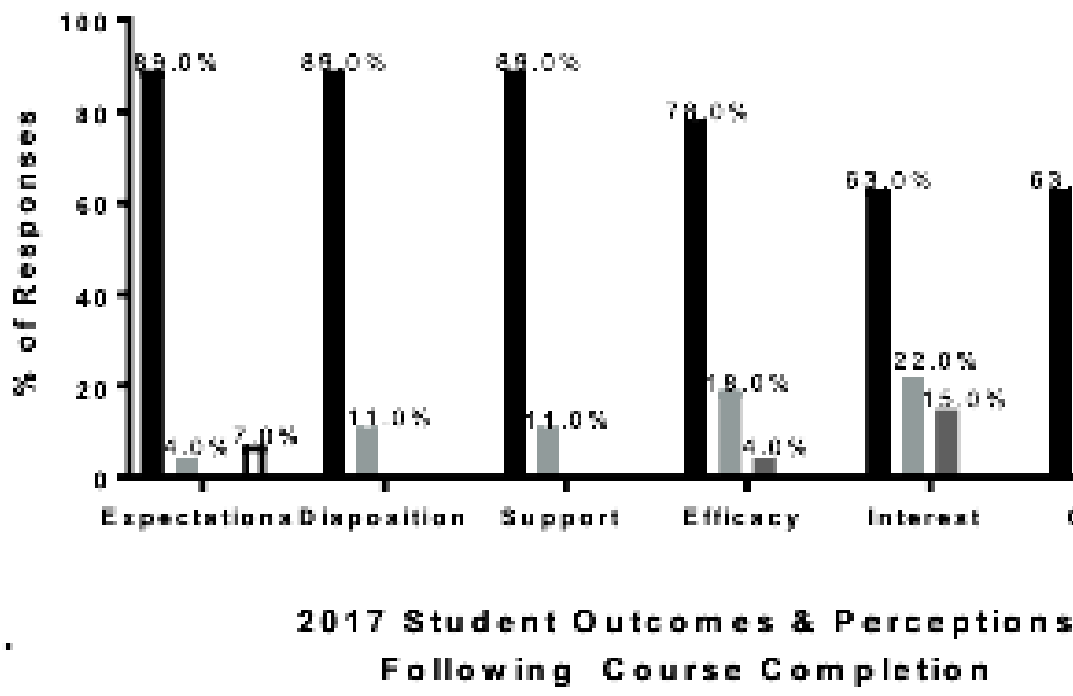

C.

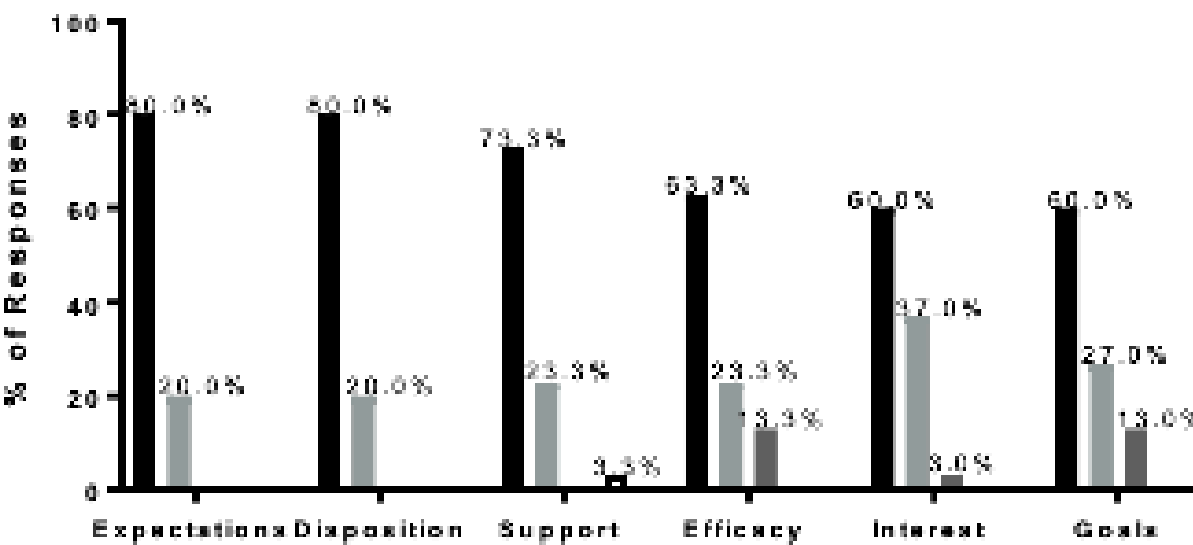

Strongly Agreelagree

Neutra

Strongly DisagroatDisagrec

No Opinior

Strongly Agredigige

Strongly DisagreeiDisagree

Wo Opinian

Comblned Responses Indlcate Positive Course outcomes

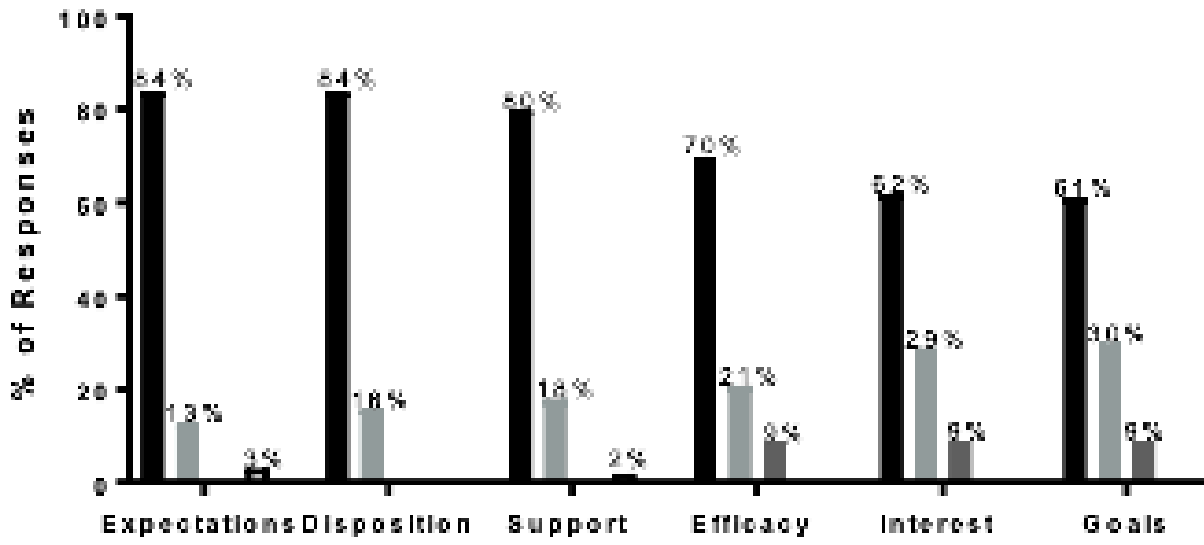

- Strangly AgreciAgrea

Neutral

Strongly D isag feer Disagree

No Opinion

Figure 4. Program Outcomes Evaluation. This survey evaluated the six social cognitive career factors: expectations, disposition, support, efficacy, interest, goals to assess impacts the course had on students who took the course in (a) 2016 (b) 2017 and (c) overall course impact from both cohorts $(\mathrm{n}=19)$.

deficits in translational science topics that leave the students naive to career options available. While integrating the subject of translational science into an already compact highschool schedule would be challenging, this change warrants investigation since the advanced state of STEM careers will soon require a specialized education at an earlier age (Dutta-Moscato et al., 2014). In addition, data from labor markets indicate that possessing a set of core cognitive knowledge, skills, and abilities associated with a STEM education are necessary for both STEM occupations and non-STEM 
Table 8a. Student responses to open-ended questions. The three open-ended questions in the Program Outcome Evaluation that directly addressed course material and content are included along with sample student responses.

Question and Description

Student Quotes

"I knew nothing about clinical trials before the course."

Question:

Translational Science Process

Description: How the course improved understanding of therapeutic modalities

"I learned why the cost of healthcare is so high."

"With the proper instruction, I was able to understand how medicines are implemented into the clinical setting to usage in the real world, which greatly improved my knowledge for the field of medicine and how these processes assist in implementing the ideas found in the lab to the rest of the population."

"The course taught me all about the process of moving a product from the lab to clinical trials. I now feel comfortable in my understanding of the process, and its importance in developing current research."

"It makes you think about the actual process of medical development, rather than the development itself. Before this course I had no idea that the process of implementing medicine would be so complex."

"The Final Project made me take my small lab-based experiment in SSTP, figure out how it would actually be used in a clinical setting, and recognize the many steps that would need to be taken to make my project accessible to the public. It really helped me widen my perspective of the possible impacts of my primarily code-based work."

"The final project helped me present an idea for a treatment through culmination and summary of the different

Question: Application of Course Content

Description: How the final project helped apply what was taught in the course stages in translational science. Though the idea was simple and the path ideal, the project was helpful in cementing the course's info into my memory."

"It made me have to research more about Translational Science and learn about how one would plan the different phases."

"It helped me to apply the steps that I've learned to a product that I am interested in."

"The final project applied my newfound knowledge from the Translational Science course through not just the research that was done in order to create the therapeutic modalities, but also understanding what steps must be taken in order to implement the cure that I desired to implement."

"In the short-term, I am aiming for medical school. I have always wanted to be a community clinic doctor since before SSTP, but this course has inspired me to see my profession in another light, as a bridge between new scientific developments and the needs of my patients. In other words, in the long term, I aim to also be involved in Stage 2 or 3 of translational science and contribute my patients' insights and my time to helping make these new modalities effective and accessible."

"It allowed me to want to go into research and hopefully in the long-term create a product that can benefit people medically."

"Half way through my summer research, I realized that I am not really into lab research, so simultaneously taking this translational science course gave me an opportunity to see what's beyond a lab setting. I know I still love science, but I am no longer stubborn in choosing a traditional science major like biology, physics, or chemistry. In fact, as a first year college student, I am currently considering a major in Medicine, Literature \& Society, which could be my short-term goal. In the long term, I haven't though through what I want to pursue in life, but I will definitely keep an open mind."

"The Translational Science class helped me to better understand what I wanted to do throughout and after college. Because of this course, I feel empowered to continue research in science, but I want to go beyond just conducting research. Specifically, I want to see the connections between science research and public policy. Because of my interest, I want to hopefully major in Neuroscience and Public Policy; this is not an established major at my college, but I am looking to create this major so that I can further pursue my interests."

"In regards to the short-term goals, I am definitely more appreciative of the researching process behind therapeutic modalities, and as I go into college, I hope to see these processes again in action and hopefully partake in them as well. However, long-term wise, I decided that I was more interested in actually testing the therapeutic modalities rather than developing them, and so, I am now able to narrow down my career choices even further." positions in all job sectors and types of positions (Carnevale et al., 2013).

The goal of this study was to develop and validate a high-school geared curriculum using educational resources beyond the textbook to expose young students to the fundamentals of translational science. The curriculum encompassed the five phases of translational science that guided students through the intricate process of bringing medical research into clinical use, commonly known as bench-tobedside. In addition to the didactic lectures, demonstrations of the tools, platforms, and practical skills necessary for success as a translational scientist were provided. These included how to perform scientific literature searches (i.e. PubMed, Google Scholar, Clinical Trials.gov) and how to 
Table 8b. Thematic codes across three of the open-ended questions. Student answers were transcribed, and three categories were identified based on response frequency. These categories were learning, influence, and understanding. The description of how each category was defined is included in the table.

Category and Description

CATEGORY:

Learning

DESCRIPTION:

Learning the subject of translational science and its application

CATEGORY:

Influence

DESCRIPTION:

Impacts on future goals

CATEGORY:

Understanding

DESCRIPTION:

Overall understanding of discovery, development, and implementation of translational science

\section{Student Quotes}

"Helped me learn how drugs are moved through the system."

"I was previously unaware of translational science, but I learned not only what it was, but also how to apply it."

"I learned that there are various ways to work in the medical fields. "

"I learned about Physician's Assistants, and now, I want to become one."

"I am now aware of how translational science plays into my future career path."

"I prefer engineering, but that doesn't mean translational science was a waste of time. I can see the development of tools/processes to be much the same as the development of clinical things. Thus this class taught me about how I will need to conduct my engineering research, and how I will apply it."

"The course increased my interest in fields of study that had more immediate, practical applications. There's little point pursuing something just to learn more, research just for the sake of research. I'm also now interested in fields like Materials Science, which has great potential to be translatable."

"This course influenced my interest in bench-side research."

"I already had a career path in mind, but the Translational Science course helped me consider the importance of research in STEM and made me think more about pursuing research as a career."

"The translational science course did not really influence my short or long term goals, because to begin with, I was a lot more interested in engineering, rather than biology."

"It allowed me to understand and realize that there are multiple steps a scientist has to go through before their product can go on the market."

"I understand the difficulties involved in pushing through a scientific discovery, and the grit, passion, and determination it takes to be the person(s) pushing it through."

"The translational science course helped to improve my overall understanding of how therapeutic modalities are transitioned into the clinical setting. Through this course, I learned that there is more to research than just sitting in a laboratory. It takes years for research to be finalized and approved in order to be utilized by the general public and, from this knowledge, I have gained a new appreciation for scientific research." effectively read a scientific article. Hands-on activities such as 'clinical problem solving with engineering' and 'design a paper' (Table 3) directly applied lecture materials to provide students with a mini-practicum experience. The curriculum was designed using the informal learning style that is voluntary, self-directed, and motivated by personal needs and interests (Sorohan, 1993). Conducting the course at a university gave students exposure to a professional setting and provided opportunities for direct interaction with career professionals in both academia and industry (Knox et al., 2003).

The impact of the translational science curriculum was evaluated in two separate assessments: an immediate course evaluation (End-of-Course Evaluation) and a follow-up survey (Program Outcomes Evaluation). The majority of students indicated that the course held their interest and had met their expectations on the immediate course evaluation. Although a small population of the students were apathetic or uninterested in the topic of Translational Science per survey responses, students still applied themselves in the final projects by providing adequate background information $(100 \%)$ on a project of choice and completed the project as directed. Nearly all the students $(95 \%)$ felt that adequate background information was provided in the course content to understand the major topics, indicating the methods of teaching were effective for multiple learning styles (visual, aural, verbal, physical).

To assess impacts on future career endeavors, a follow-up survey was conducted and distributed via Qualtrics six months or more after course completion. Of note, this survey was administered during a meaningful transition time for the high-school students, as they are completing their secondary education. The follow-up survey was based on the validated Social Cognitive Career Theory (SCCT) to predict student interests and career choices (R. Lent et al., 1994). The impact of the course was evaluated according to a five-point Likert scale of six categories of personal and individual development: expectations, disposition, support, efficacy, interest, and goals. The categories most positively influenced were expectations, disposition, and support, with very similar positive response rate of $84 \%, 84 \%$, and $80 \%$, respectively. This suggests that most of the students had a favorable outlook of Translational Science as it relates to 
improving clinical medicine, even if they aren't as interested in going into the field. Furthermore, the curriculum provided adequate fundamentals and resources to understand the course aims and professional growth, despite differences in students' interests and backgrounds. The two Q\&A career panels provided high-school students with real-life contacts to probe about steps necessary to pursue a STEM career and possible career choices stemming from translational science. There was so much information discussed over a limited timeframe that self-efficacy would likely improve with more time and practice. Of importance, all six categories had a majority positive impact (agree/strongly agree ratings) from the course, and no category had a greater than $10 \%$ negative response ratings (disagree/strongly disagree). This survey shows that students at the high school level can appreciate the value of translational science even though they are early in their STEM-derived career paths. With proper support and curriculum, the students can have a positive disposition towards a STEM career.

While the student surveys and responses demonstrate the efficacy of the class, there are numerous limitations and considerations to discuss. The students entered the program with an initial interest in STEM and self-selected for this seminar. If student enrollment had not been through the SSTP program, or if students were placed randomly into seminars, there could have been less of an interest or overall course effectiveness. Furthermore, the sample size for this study was limited to the 20 students that were enrolled when the seminar was conducted in 2016 and 2017. Increased seminar offerings with higher student numbers would strengthen the validation of the curriculum's efficacy. Lastly, there is always individual student variability that accompanies these programs in regards to student content, knowledge, and interest (Burgin et al., 2012). A long-term follow-up evaluation given more than four years after course completion would be valuable to assess if students pursued STEM-related studies or careers. Further evaluations are also necessary to determine the impact of this curriculum in a broader setting and its alignment with Common Core Standards, Next Generation Science Standards, and State of Florida Education Standards. Following Florida Department of Education Standards, this course could constitute as a STEM Program of Study as it is a curriculum driven by problem-solving, discovery, and exploratory learning in an actively engaging environment.

\section{AUTHOR INFORMATION Corresponding Author}

Correspondence concerning this article should be addressed to Andrea Lin, University of Florida, 1275 Center Drive, PO Box 100275, Gainesville, FL 32610. Contact: alin527@ufl.edu, (850)218-2268

\section{ACKNOWLEDGMENTS}

We thank Dr. Wayne T. McCormack, Director, Clinical and Translational Science Doctoral Programs, for his direction in this paper and for introducing us to the topic of translational science. We are grateful to him for helpful discussions. We would like to thank the University of Florida Clinical and Translational Science Institute, Vice President Pearson, and its associated programs for providing us with the necessary education components to complete this manuscript. We are grateful to Dr. Gregory Hudalla for his support and resources in the Clinical Engineering Problem activity. Finally, we would like to thank Dr. Gregory Hudalla, Dr. Clayton Mathews, and Dr. Thomas Schmittgen for the inspiration to mentor future students and their continued support in our career pursuits.

\section{ABBREVIATIONS}

CPET: Center of Precollegiate Education and Training; SCCT: Social Cognitive Career Theory; SSTP: Student Science Training Program; STEM: Science, Technology, Engineering, Math;

\section{REFERENCES}

Blumberg, R. S., Dittel, B., Hafler, D., von Herrath, M., and Nestle, F. O. (2012). Unraveling the autoimmune translational research process layer by layer. Nature Medicine, 18(1), 35-41. Retrieved from https://www.ncbi.nlm.nih.gov/ pubmed/22227670

Burgin, S., Sadler, T., and Koroly, M. J. (2012). High School Student Participation in Scientific Research Apprenticeships: Variation in and Relationships Among Student Experiences and Outcomes. In (Vol. 42, pp. 439-467). Research in Science Education.

Carnevale, A. P., Smith, N., and Melton, M. (2011). STEM: Science Technology Engineering Mathematics. State-Level Analysis In. Education Resources Information Center: Institute of Education Sciences.

Dutta-Moscato, J., Gopalakrishnan, V., Lotze, M. T., and Becich, M. J. (2014). Creating a pipeline of talent for informatics: STEM initiative for high school students in computer science, biology, and biomedical informatics. Journal of Pathology Informatics, 5(1), 12. Retrieved from https://www. ncbi.nlm.nih.gov/pubmed/24860688.

Flores, L. S., LB. Armstrong, P.I., and Velez, A.D. (2006). Validity of the strong Interest Inventory and Skills Confidence Inventory with Mexican American high school students. In (Vol. 14, pp. 183-202). Journal of Career Assessment.

Fort, D. G., Herr, T. M., Shaw, P. L., Gutzman, K. E., and Starren, J. B. (2017). Mapping the evolving definitions of translational research. Journal of Clinical and Translational Science, 1(1), 60-66. Retrieved from https://www.ncbi.nlm. nih.gov/pubmed/28480056. 
Gannon, F. (2014). The steps from translatable to translational research. EMBO Reports, 15(11), 1107-1108. Retrieved from https:/www.ncbi.nlm.nih.gov/pubmed/25296643. doi:10.15252/embr.201439587

Glaser, B. (1965). The Constant Comparative Method of Qualitative Analysis. In (Vol. 12, pp. 436-445). Social Problems: JSTOR.

Kier, M., Blanchard, M., Osborne, J., and Albert, J. (2014). The Development of the STEM Career Interest Survey (STEMCIS) In (Vol. 44, pp. 461-481). Research in Science Education.

Knox K.L., Moynihan J., and Dina, M. (2003). Evaluation of short-term impact of a high school summer science program on students' perceived knowledge and skills. Journal of Science Education and Technology, 12(4), 471-478.

Lent, R. (2004). Toward a unifying theoretical and practical perspective on well-being and psychosocial adjustment. In (Vol. 51, pp. 482-509). Journal of Counseling Psychology.

Lent, R., Brown, S., and Hackett, G. (1994). Toward a unifying social cognitive theory of career and academic interest, choice, and performance. In (Vol. 45, pp. 79-122): Journal of Vocational Behavior.

Lent, R. W. B., and Brown, S. (2000). Contextual supports and barriers to career choice: a social cognitive analysis. In (Vol. 37, pp. 36-49). Journal of Counseling Psychology.

Likert, R. (1932). A technique for measurement of attitudes. In (Vol. 22, pp. 5-55). Archives of Psychology.

Luke, D. A., Carothers, B. J., Dhand, A., Bell, R. A., Moreland-Russell, S., Sarli, C. C., and Evanoff, B. A. (2015). Breaking down silos: mapping growth of cross-disciplinary collaboration in a translational science initiative. Clinical and Translational Science, 8(2), 143-149. Retrieved from https://www.ncbi.nlm.nih.gov/pubmed/25472908.

Manson, S., Martinez, D., Buchwald, D., Rubio, D., and Moss, M. (2015). Vision, identity, and career in the clinical and translational Sciences: Building upon the formative years. Clinical Translational Science, 8, 568-572. Retrieved from https://ascpt.onlinelibrary.wiley.com/doi/epdf/10.1111/ cts. 12316.

NCATS. (2018). Clinical Translational Science Awards Program. National Center for Advancing Translational Sciences. Retrieved from https://ncats.nih.gov/ctsa

Nearing, K. A., Hunt, C., Presley, J. H., Nuechterlein, B. M., Moss, M., and Manson, S. M. (2015). Solving the puzzle of recruitment and retention-Strategies for building a robust clinical and translational research workforce. Clinical and Translational Science, 8(5), 563-567. Retrieved from https://www.ncbi.nlm.nih.gov/pubmed/26009882.

Noonan, R. (2017). STEM Jobs: 2017 Update. Retrieved from Economics \& Statistics Administration United States Department of Commerce

Rothwell, J. (2013). The Hidden STEM Economy. Retrieved from https://www.brookings.edu/research/the-hidden-stem-economy/
Rubio, D. M., Schoenbaum, E. E., Lee, L. S., Schteingart, D. E., Marantz, P. R., Anderson, K. E., Platt, L.D., Baez, A., and Esposito, K. (2010). Defining translational research: implications for training. Academic Medicine, 85(3), 470-475. Retrieved from https://www.ncbi.nlm.nih.gov/ pubmed/20182120.

Secretary (2016). FACT SHEET: Advancing Active STEM Education for Our Youngest Learners [Press release]. Retrieved from https://innovation.ed.gov/files/2017/01/ FACT-SHEET_Advancing-Active-STEM-Education-for-Our-Youngest-Learners.pdf

Sorohan, E. G. (1993). We do; Therefore, we learn. Training and Development, 47(10).

Vagias, W. (2006). Likert-type Scale Response Anchors. In. Research Development, Department of Parks, Recreation and Tourism Management, Clemson University: Clemson International Institute for Tourism. 